\title{
Stargazin and Other Transmembrane AMPA Receptor Regulating Proteins Interact with Synaptic Scaffolding Protein MAGI-2 in Brain
}

\author{
Fang Deng, Maureen G. Price, Caleb F. Davis, Mayra Mori, and Daniel L. Burgess \\ Department of Neurology, Baylor College of Medicine, Houston, Texas 77030
}

The spatial coordination of neurotransmitter receptors with other postsynaptic signaling and structural molecules is regulated by a diverse array of cell-specific scaffolding proteins. The synaptic trafficking of AMPA receptors by the stargazin protein in some neurons, for example, depends on specific interactions between the C terminus of stargazin and the PDZ [postsynaptic density-95 (PSD-95)/Discs large/zona occludens-1] domains of membrane-associated guanylate kinase scaffolding proteins PSD-93 or PSD-95. Stargazin [Cacng2 $\left(\mathrm{Ca}^{2+}\right.$ channel $\gamma 2$ subunit)] is one of four closely related proteins recently categorized as transmembrane AMPA receptor regulating proteins (TARPs) that appear to share similar functions but exhibit distinct expression patterns in the CNS. We used yeast two-hybrid screening to identify MAGI-2 (membrane associated guanylate kinase, WW and PDZ domain containing 2) as a novel candidate interactor with the cytoplasmic $\mathrm{C}$ termini of the TARPs. MAGI-2 [also known as S-SCAM (synaptic scaffolding molecule)] is a multi-PDZ domain scaffolding protein that interacts with several different ligands in brain, including PTEN (phosphatase and tensin homolog), dasm1 (dendrite arborization and synapse maturation 1), dendrin, axin, $\beta$ - and $\delta$-catenin, neuroligin, hyperpolarization-activated cation channels, $\beta 1$-adrenergic receptors, and NMDA receptors. We confirmed that MAGI- 2 coimmunoprecipitated with stargazin in vivo from mouse cerebral cortex and used in vitro assays to localize the interaction to the C-terminal -TTPV amino acid motif of stargazin and the PDZ1, PDZ3, and PDZ5 domains of MAGI-2. Expression of stargazin recruited MAGI-2 to cell membranes and cell-cell contact sites in transfected HEK-293T cells dependent on the presence of the stargazin -TTPV motif. These experiments identify MAGI-2 as a strong candidate for linking TARP/AMPA receptor complexes to a wide range of other postsynaptic molecules and pathways and advance our knowledge of protein interactions at mammalian CNS synapses.

Key words: stargazin; TARP; MAGI-2; S-SCAM; MAGUK; PDZ; AMPA

\section{Introduction}

Stargazin is a neuronal membrane-spanning protein of $\sim 40 \mathrm{kDa}$ identified by positional cloning as the product of the mouse locus stargazer (Letts et al., 1998). Mutations in stargazin are associated with epilepsy, ataxia, and other neurological deficits (Noebels et al., 1990; Qiao et al., 1998). The gene symbol Cacng2 ( $\mathrm{Ca}^{2+}$ channel $\gamma 2$ subunit) was assigned to the stargazer gene on recognition of the fact that the encoded protein shared $25 \%$ amino acid (aa) identity with the skeletal muscle Cacng1, the closest known relative at that time. Subsequent studies identified six related genes (Cacng3-Cacng8) encoding proteins $(\gamma 3-\gamma 8)$ with varying degrees of homology to $\gamma 1$ and $\gamma 2$ (Black and Lennon, 1999; Burgess et al., 1999, 2001). Cacng2-Cacng8 are expressed in fetal and adult brain, and Cacng4-Cacng7 are transcribed in several addi-

\footnotetext{
Received May 1, 2006; revised June 14, 2006; accepted June 14, 2006.

This work was supported by National Institutes of Health-National Institute of Neurological Disorders and Stroke Grant NS042632. We are grateful to H. Luo (Baylor College of Medicine) for providing expression vectors and Dr. C. Zilinski (Baylor College of Medicine) for helpful discussions regarding this manuscript.

Correspondence should be addressed to Dr. Daniel L. Burgess, Department of Neurology, Baylor College of Medicine, One Baylor Plaza, NB222, Houston, TX 77030. E-mail: dburgess@bcm.tmc.edu.

DOI:10.1523/JNEUROSCI.1851-06.2006

Copyright $\odot 2006$ Society for Neuroscience $\quad$ 0270-6474/06/267875-10\$15.00/0
}

tional tissues (Burgess et al., 2001; Chu et al., 2001; Kious et al., 2002).

Coexpression of the $\gamma 2-\gamma 8$ proteins modulates the biophysical properties of variously reconstituted L-, P/Q-, N-, or T-type voltage-gated $\mathrm{Ca}^{2+}$ channels in Xenopus oocytes or cultured mammalian cells (Kang et al., 2001; Rousset et al., 2001; Moss et al., 2002, 2003), but no evidence has been obtained to confirm that they perform this role in vivo. Hashimoto et al. (1999) suggested a very different function for the stargazin protein and showed that stargazer cerebellar granule cells lacked the fast component of EPSCs mediated by AMPA receptors (AMPARs) at mossy fiber-granule cell synapses. The absence of functional AMPARs at these synapses was explained when stargazin was found to be essential for the membrane localization and synaptic targeting of AMPARs in cerebellar granule neurons (Chen et al., 2000). Subsequent analyses extended these results to support a central role for $\gamma 2, \gamma 3, \gamma 4$, and $\gamma 8$ (but not $\gamma 1, \gamma 5, \gamma 6$, or $\gamma 7$ ) in the AMPAR pathway (Chetkovich et al., 2002; Schnell et al., 2002; Tomita et al., 2004; Yamazaki et al., 2004; Priel et al., 2005; Turetsky et al., 2005; Vandenberghe et al., 2005). The $\gamma 2, \gamma 3, \gamma 4$, and $\gamma 8$ proteins, which form a discrete phylogenetic subgroup, were designated transmembrane AMPA receptor regulating pro- 
teins (TARPs) in recognition of these newly discovered functions (Tomita et al., 2003).

The ability of the TARPs to regulate AMPAR function is coordinated, in turn, by other TARP-binding proteins. For example, AMPAR synaptic targeting in some neurons is regulated by stargazin $(\gamma 2)$ interactions with the proteins postsynaptic density-95 (PSD-95) or PIST (protein interacting with TC-10) (Chen et al., 2000; Cuadra et al., 2004). Stargazin also interacts in vivo with the microtubule-associated protein MAP1A (Ives et al., 2004). We used yeast two-hybrid library screening approaches to identify additional ligands that interacted with the $\gamma$ proteins. Here, we present evidence that $\gamma 2$ and other TARPs $(\gamma 3, \gamma 4$, and $\gamma 8$ ) associate with the multi-PDZ (PSD-95/Discs large/zona occludens-1) domain neuronal scaffolding protein MAGI-2 (membrane associated guanylate kinase, WW and PDZ domain containing 2) in vivo and identify the specific protein domains that mediate these interactions. As a result of this study, MAGI-2 can be considered a strong candidate for physically linking TARP/AMPAR complexes to a wide range of other important postsynaptic molecules and pathways in neurons.

\section{Materials and Methods}

Cacng protein alignment. The predicted cytoplasmic C-terminal tails of the mouse Cacng $(\gamma)$ proteins were defined previously using orthologous human sequences (Burgess et al., 2001). These C-terminal amino acid sequences were aligned using ClustalW version 1.8 (Thompson et al., 1994). The inferred phylogenetic relationship among the $\gamma$ proteins was described previously (Price et al., 2005).

Antibodies and immunoblotting. Antibodies used include the following: rabbit polyclonal antibodies directed against mouse $\gamma 2$ amino acids 305-323 (KDSKDSLHANTANRRTTPV) (07-577; Upstate Biotechnology, Lake Placid, NY), which also recognize $\gamma 3, \gamma 4$, and $\gamma 8$ (i.e., antiTARP); rabbit polyclonal antibodies directed against mouse MAGI-2/SSCAM amino acids 391-408 (SQSVPDITDRPPHSLHSM) (M2441; Sigma, St. Louis, MO), which is in the linker between the PDZ1 and PDZ2 domains; mouse monoclonal anti-c-myc (Becton Dickinson, Mountain View, CA); and anti- $\beta$-actin (A5316; Sigma). For immunoblotting, protein extracts were resolved by SDS-PAGE and transferred to nitrocellulose membranes (Pall Gelman Laboratory, Ann Arbor, MI). Primary antibodies were diluted in 5\% blocking milk (Bio-Rad, Hercules, CA) in TBS (anti-stargazin at $1 \mu \mathrm{g} / \mathrm{ml}$, anti-MAGI-2/S-SCAM at $1: 500$, anti-c-myc at $2 \mu \mathrm{g} / \mathrm{ml}$, and anti- $\beta$-actin at 1:5000) and incubated with membranes for $3 \mathrm{~h}$ at room temperature. Horseradish peroxidaseconjugated secondary antibodies and enhanced chemiluminescence (Amersham Biosciences, Piscataway, $\mathrm{NJ}$ ) were used to visualize reacting proteins.

Construction of expression vectors. A full-length mouse MAGI- $2 \beta / \mathrm{S}$ SCAM cDNA clone (IMAGE clone 6847238; GenBank accession number BC059005) was obtained from Invitrogen (Carlsbad, CA). MAGI-2/SSCAM and Cacng2 expression vectors were constructed using the Gateway System (Invitrogen) according to the protocols of the manufacturer. Briefly, MAGI-2/S-SCAM (amino acids 1-1112), GKW [amino acids $1-233$, containing both the granulate kinase (GK) and WW domains], PDZ1-5 (amino acids 245-1112), PDZ1-3 (amino acids 245-712), PDZ4-5 (amino acids 727-1112), PDZ1 (amino acids 245-393), PDZ2 (amino acids 404-556), PDZ3 (amino acids 583-732), PDZ4 (amino acids 723-963), and PDZ5 (amino acids 922-1112) were subcloned into pENTR/D and then recombined into pDEST15, which has an N-terminal glutathione $S$-transferase (GST) tag. pENTR-MAGI-2/S-SCAM (amino acids 1-1112) and pENTR-GKW (amino acids 1-233) were recombined into pDEST53 (Invitrogen), which has an $\mathrm{N}$-terminal green fluorescent protein (GFP) tag. To generate His $_{6}$-tagged c-myc-Cacng2 (amino acids 204-323) and $\mathrm{His}_{6}$-tagged c-myc-Cacng2 $\Delta$ TTPV (amino acids 204319 ), PCR products were amplified from pGBKT7-Cacng2 (amino acids 204-323) containing an N-terminal c-myc tag and then subcloned into pENTR/D and recombined into pDEST17 (Invitrogen), which has an $\mathrm{N}$-terminal $\mathrm{His}_{6}$ tag. Cacng2 (amino acids 1-323) and Cacng2 $2 \mathrm{TTPV}$ (amino acids 1-319) were subcloned into pHcRED1-C1 (Becton Dickinson), which has an N-terminal HcRED1 far-red fluorescent protein tag that can be used to monitor protein localization in vivo. The sequences of oligonucleotide primers used to construct vectors in this study are provided in supplemental Table 1 (available at www.jneurosci.org as supplemental material).

Yeast two-hybrid screen. Yeast two-hybrid screens were performed using the Matchmaker kit (Becton Dickinson) according to the protocols of the manufacturer. Briefly, the cytoplasmic C-terminal tail of mouse $\gamma 2$ (amino acids 204-323), $\gamma 3$ (amino acids 198-315), $\gamma 4$ (amino acids 204-327), $\gamma 5$ (amino acids 200-275), $\gamma 7$ (amino acids 201-275), or $\gamma 8$ (amino acids 224-423) was subcloned into the bait vector pGBKT7. A 9-12 week postnatal mouse brain cDNA library in the prey vector pACT2 (Becton Dickinson), pretransformed into yeast Y187 cells, was screened by separate matings with AH109 yeast cells carrying each bait plasmid and plating onto high-stringency selective media synthetic dropout (SD)-Ade/-His/-Leu/-Trp. Colonies that grew in 3-6 d were picked and rescreened on SD-Ade/-His/-Leu/-Trp with the addition of 5-bromo-4-chloro-3-indolyl- $\alpha$-D-galactopyranoside. Blue colonies from this screen were selected for additional analysis.

Clone analysis and yeast cotransformation test. Plasmid DNA was extracted from each positive yeast clone by $3.6 \mathrm{U} / \mu \mathrm{l}$ lyticase and electroporated into TOP10 Escherichia coli competent cells (Invitrogen). Purified plasmids were sequenced using the primer PACT-Q (supplemental Table 1 , available at www.jneurosci.org as supplemental material). The identity of prey sequences was determined by BLAST (Basic Local Alignment Search Tool) searches of National Center for Biotechnology Information (NCBI) databases (www.ncbi.nlm.nih.gov/BLAST). Positive interactions between bait and prey were verified by cotransforming each pair of bait and prey plasmids into AH109 cells, followed by duplicate plating onto high-stringency selective media: SD-Ade/-His/-Leu/-Trp [quadruple drop-out (QDO)] and SD-Leu/-Trp [double drop-out (DDO)]. Survival on QDO indicated that both plasmids were present and the proteins interacted. Survival on DDO indicated only that both plasmids were present and provided data on mating efficiency. Cotransformation with the empty pGBKT7 vector and pGBKT7 containing p53 protein coding sequences was used to eliminate false-positive candidate interactors. The strength of interactions between candidate interactors and different Cacng proteins or controls (p53, T7) were estimated visually by the growth ratio on $\mathrm{QDO} / \mathrm{DDO}$ medium:,$- 0 ;+/-,<0.01 ;+, 0.01-0.1$; ,$++ 0.1-0.5$; and,$+++>0.5$.

Expression of MAGI-2 and coimmunoprecipitation with $\gamma$ proteins from mouse brain. Adult mouse cerebral cortex, cerebellar, and hippocampal tissue were rapidly dissected from wild-type (C57BL/6) and stargazer (stg/stg, Cacng2-null) mice, frozen in liquid nitrogen, and stored at $-80^{\circ} \mathrm{C}$ until required. Tissues were rapidly thawed and homogenized in radioimmunoprecipitation assay (RIPA) buffer ( $50 \mathrm{~mm} \mathrm{NaCl}, 1.0 \%$ IGEPAL CA-630, 0.5\% sodium deoxycholate, $0.1 \%$ SDS, and $50 \mathrm{~mm}$ Tris, $\mathrm{pH}$ 8.0) (Sigma) plus $1 \mathrm{~mm}$ phenylmethylsulfonyl fluoride containing a 1:100 dilution of mammalian protease inhibitor cocktail (Sigma). The brain region homogenates were centrifuged at $2900 \times g$ for $10 \mathrm{~min}$ at $4^{\circ} \mathrm{C}$ to eliminate cell debris. The supernatant was then centrifuged at $15,000 \times g$ for $10 \mathrm{~min}$. Samples were separated on SDS-polyacrylamide gels for immunoblotting analysis with anti-MAGI- 2 and anti- $\beta$-actin. For immunoprecipitation experiments, the high-speed supernatant of each brain extract was precleared by incubation with $50 \mu$ lanti-rabbit IgG beads (eBioscience, San Diego, CA) at $4^{\circ} \mathrm{C}$ for $1 \mathrm{~h}$ with gentle mixing. The precleared brain extract was then incubated with $5 \mu \mathrm{g}$ of anti-stargazin (Upstate Biotechnology) antibodies for $1 \mathrm{~h}$ at $4^{\circ} \mathrm{C}$, and then $50 \mu \mathrm{l}$ of anti-rabbit IgG beads was added for the next $2 \mathrm{~h}$ of incubation. Rabbit preimmune serum (Sigma) was used in place of antibodies for the negative control. The beads were washed three times with RIPA buffer, and the immunoprecipitates were eluted with $2 \times$ SDS sample buffer and separated by SDS-PAGE. Immunoblotting analysis was performed with both anti-TARP and anti-MAGI-2/S-SCAM antibodies.

Cacng protein preparations from HEK-293T cells. Cacng2, Cacng3, Cacng4, and Cacng8 coding regions were subcloned into the bicistronic pIRES2-enhanced GFP (EGFP) vector (Becton Dickinson). The Cacng8 coding region was also subcloned into pEGFP-C1 (Becton Dickinson) 
A

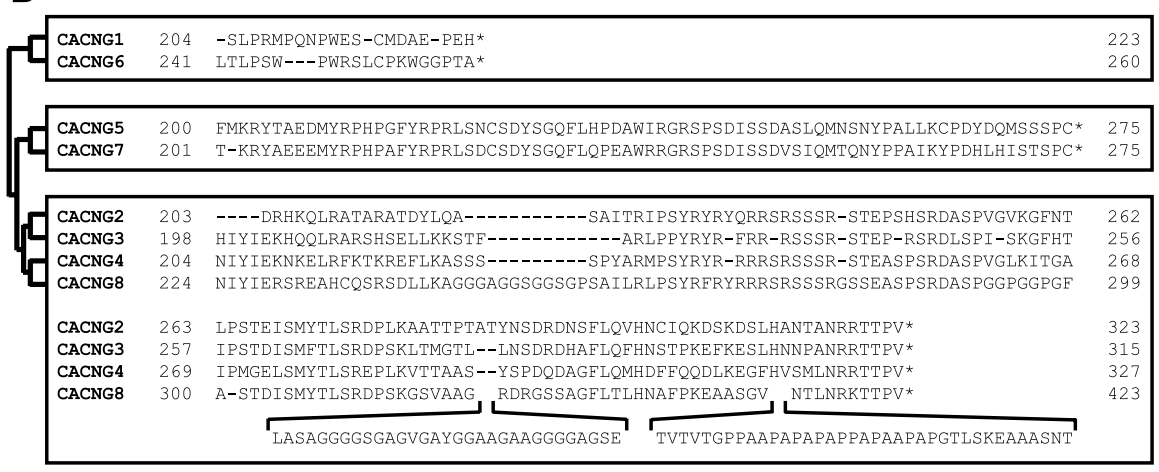

Figure 1. Cacng protein segments used for yeast two-hybrid screening. A, Model of Cacng $(\gamma)$ protein topology, showing a cytoplasmic $\mathrm{N}$ terminus, four transmembrane segments, two extracellular loops, and a cytoplasmic C terminus. All eight $\gamma$ proteins are similar in size except for the variable-length C termini, labeled on the model for each indicated protein. The cytoplasmic tails of all $\gamma$ proteins except for the smaller $\gamma 1$ and $\gamma 6$ were used as baits for yeast two-hybrid screens. The filled arrowhead marks the beginning of each bait, and the open arrowheads mark the ends, which correspond to the C terminus of each protein. $\boldsymbol{B}$, Alignment of the $\gamma$ protein C-termini amino acid sequences (bait regions). The sequences are grouped in boxes by similarity with the inferred evolutionary relationships indicated by branching lines at left (Price et al., 2005). Note that the C-terminal tail of $\gamma 8$ is longer than that of the related $\gamma 2, \gamma 3$, and $\gamma 4$ proteins, primarily because of glycine-alanine and proline-alanine expansions (shown isolated at bottom). The polyclonal anti-TARP antibody used in this study was directed against the C-terminal 19 aa of mouse Cacng2.

for production of GFP-Cacng8 protein. These constructs were transfected into HEK-293T cells using the Fugene 6 transfection reagent (Roche, Indianapolis, IN). After $48 \mathrm{~h}$, cells were harvested and solubilized using $2 \times$ SDS sample buffer to obtain crude lysis samples for immunoblotting. Alternatively, membrane proteins were prepared using the celLytic MEM Protein Extraction kit (Sigma) according to the protocol of the manufacturer. Briefly, HEK-293T cells were lysed using the lysis and separation working solution containing protease inhibitor cocktail and PMSF. The hydrophobic and hydrophilic proteins were separated by a series of incubation and centrifugation steps. Hydrophobic fractions containing the $\gamma$ membrane proteins were used for immunoblotting analyses and in vitro binding assays.

Fusion protein preparation and in vitro binding assays. Expression of $\mathrm{N}$-terminally GST-tagged MAGI-2 fusion proteins or $\mathrm{His}_{6}$-tagged c-myc-Cacng fusion proteins was induced in the E. coli strain BL21-AI (Invitrogen) with $0.2 \% \mathrm{~L}$-arabinoside. Bacterial lysates were prepared by mild sonication in NETN buffer (20 mM Tris, pH 8.0, $100 \mathrm{~mm} \mathrm{NaCl}, 1 \mathrm{~mm}$ EDTA, and 0.5\% NP-40) plus $1 \mathrm{~mm}$ PMSF and protease inhibitor cocktail (1:100; Sigma). His-tagged Cacng fusion proteins were purified by binding to $\mathrm{Ni}^{2+}$-charged nitrilotriacetic acid silica columns (Qiagen, Valencia, CA) and elution with $500 \mathrm{~mm}$ imidazole in PBS. In vitro binding studies were performed as follows: first, GST-tagged fusion proteins were incubated with glutathione-Sepharose $4 \mathrm{~B}$ beads (Amersham Biosciences, Little Chalfont, UK) in NETN buffer plus protease inhibitors for $2 \mathrm{~h}$ at $4^{\circ} \mathrm{C}$ with constant agitation, and then the beads were washed three times with NETN buffer to remove unbound protein. Glutathione-Sepharose $4 \mathrm{~B}$ beads with $\sim 2 \mu \mathrm{g}$ of GST or GST-tagged MAGI-2 fusion proteins immobilized on them were mixed with Cacng2-containing membrane proteins prepared from HEK-293T cells or with purified $\mathrm{His}_{6}$-tagged c-myc-Cacng 2 proteins. The mixtures were incubated with gentle rocking for $3 \mathrm{~h}$ at $4^{\circ} \mathrm{C}$. The beads were washed three times with NETN buffer, and bound proteins were eluted with $2 \times$ SDS sample buffer or with glutathione elution buffer and processed by electrophoresis on $4-20 \%$
SDS-PAGE gradient gels (Bio-Rad), followed by immunoblotting with anti-c-myc or antiTARP antibodies.

Cell transfection and colocalization analysis. HEK-293T cells were routinely grown in DMEM supplemented with $10 \%$ heatinactivated fetal bovine serum (Invitrogen) and cultured at $37^{\circ} \mathrm{C}$ under humidified $5 \% \mathrm{CO}_{2}$ atmosphere. Cells plated on two-well Nalge Nunc (Naperville, IL) LabTek II chamber slides at $7.5 \times 10^{4}$ cells per well were transfected singly with pHcRED1-Cacng2 (amino acids 1-323), pHcRED1-Cacng2 $\triangle$ TTPV (amino acids 1-319), or GFP-MAGI-2 (amino acids 1-1112), or doubly with pHcRED1-Cacng2 (amino acids 1-323) plus GFP-MAGI-2 (amino acids 1-1112) or pHcRED1Cacng2 $\Delta$ TTPV (amino acids 1-319) plus GFP/ MAGI-2 (amino acids 1-1112). At 24 or $48 \mathrm{~h}$ after transfection, cells were fixed with $4 \%$ (wt/ vol) paraformaldehyde in PBS at room temperature for $15 \mathrm{~min}$, and the slides were mounted with Prolong Gold anti-fade reagent containing 4',6-diamidino-2-phenylindole (DAPI) (Invitrogen). High-resolution images were taken using a DeltaVision Restoration (deconvolution) microscope (Applied Precision, Issaquah, WA) equipped with a CH350/KAF1400 CCD camera using a Zeiss (Thornwood, NY) $40 \times$ oil immersion lens (numerical aperture 1.3). Applied Precision softWoRx software was used for image acquisition, deconvolution (10 cycles, conservative mode), filtering (two-dimensional, kernel setting of 2 or 3 ), and sum-mode projection of the $0.2-\mu \mathrm{m}$-thick $z$-series images. NIH ImageJ (Abramoff et al., 2004) was used to take plot profiles of the gray value in the range of $0-255$ arbitrary units along a 3-pixel-wide line drawn across a cell in the grayscale version of a fluorescence image. The pixels/micrometer scale was set using the scale bars embedded by the softWoRx software. Plot profile data were converted into scatter plot charts using Excel software (Microsoft, Redmond, WA). All images were assembled into figures using Photoshop 6.0 (Adobe Systems, San Jose, CA).

\section{Results}

\section{Yeast two-hybrid screening}

The eight $\mathrm{Ca}^{2+}$ channel $\gamma$ subunit proteins $(\gamma 1-\gamma 8)$ encoded by the genes Cacng1-Cacng8 share similar predicted topologies, with four transmembrane segments, short cytoplasmic $\mathrm{N}$-terminal leaders, and variable-length cytoplasmic C-terminal tails (Fig. 1A). The more pronounced size and amino acid sequence differences between the C-terminal tails of these proteins compared with the transmembrane segments and extracellular loops suggested that the tail region might be particularly important for distinguishing functions and protein-protein interactions among the otherwise similar $\gamma$ subunits.

To identify novel proteins interacting with the $\gamma$ proteins in brain, we performed a series of yeast two-hybrid screens using the cytoplasmic C-terminal tails of $\gamma 2, \gamma 3, \gamma 4, \gamma 5, \gamma 7$, and $\gamma 8$ as baits (Fig. $1 B$ ). The $\gamma 1$ and $\gamma 6$ proteins were excluded because they are expressed at very low levels in brain and have $\mathrm{C}$ termini of only 20 aa (Burgess et al., 2001; Chu et al., 2001). We used each bait construct to screen $3.5 \times 10^{6}$ clones of a 9-12 week postnatal mouse brain cDNA prey library using high-stringency selection. This yielded an initial combined total of $\sim 1200$ prey clones, composed of 155 candidate $\gamma 2 \gamma 3, \gamma 4$, or $\gamma 8$ (i.e., TARP) interactors and $\sim 1000$ candidate $\gamma 5$ or $\gamma 7$ interactors. We sequenced all 155 
Table 1. Yeast two-hybrid screen results

\begin{tabular}{|c|c|c|c|c|c|c|c|c|c|}
\hline \multicolumn{2}{|l|}{ Prey } & \multicolumn{8}{|c|}{ Bait } \\
\hline Gene symbol & Protein name & $\mathrm{T} 7$ & P53 & $\gamma 2$ & $\gamma 3$ & $\gamma 4$ & $\gamma 5$ & $\gamma 7$ & $\gamma 8$ \\
\hline Dlg3 & Discs large, homolog 3; SAP102 & - & - & ++ & ++ & + & - & - & ++ \\
\hline Dlg4 & Discs large, homolog 4; PSD-95; SAP90 & - & - & +++ & +++ & +++ & - & - & +++ \\
\hline Gopc & Golgi associated PDZ and coiled-coil motif containing; PIST & - & - & + & - & + & - & - & - \\
\hline Map1a & Microtubule-associated protein $1 \mathrm{~A}$ & - & - & ++ & ++ & ++ & ++ & ++ & - \\
\hline Magi2 & $\begin{array}{l}\text { MAGI-2; S-SCAM; membrane-associated guanylate kinase, } \\
\text { WW and PDZ domain containing } 2\end{array}$ & - & - & ++ & ++ & ++ & - & - & - \\
\hline Magi3 & $\begin{array}{l}\text { MAGI-3; membrane-associated guanylate kinase, WW and } \\
\text { PDZ domain containing } 3\end{array}$ & - & - & + & - & + & - & - & + \\
\hline
\end{tabular}

Candidate proteins interacting with the cytoplasmic C-terminal tails of $\gamma 2, \gamma 3, \gamma 4, \gamma 5, \gamma 7$, or $\gamma 8$ were identified by yeast two-hybrid screening of a 9-12 week postnatal mouse brain cDNA library. Results of secondary yeast cotransformation tests are shown. MAP1A, PSD-95, SAP102, and PIST were reported previously to interact with $\gamma$ proteins. MAGI- 2 and MAGI-3 are novel candidate interactors. All prey shown were identified in primary screens by the $\gamma 2$ bait except for Dlg3, which was identified by the $\gamma 3$ bait. Secondary cotransformation data indicate the level of yeast reporter/selection gene activation (a surrogate measure of bait-prey binding affinity) with $+/-s$ sores assigned by the ratio of colony sizes on selective and permissive media (QDO/DDO):,$- 0 ;+, 0.01-0.1 ;++, 0.1-0.5 ;+++,>0.5$. T7- and p53-GAL4 fusion proteins were controls for nonspecific protein binding

TARP prey clones and a random sample $(n=64)$ of $\gamma 5$ and $\gamma 7$ prey clones. After eliminating redundancy, false reading frame artifacts, and clones representing E. coli or noncoding genomic DNA contaminants of the cDNA library, 68 prey were selected for additional analysis. Secondary yeast cotransformation tests were performed to identify false-positive interactions between bait and prey attributable to nonspecific interactions. Of the 68 selected prey, 31 interacted with the negative control protein p53 or activated the yeast reporter gene in the absence of bait and were determined to be likely false positives. Among the other 37 prey, four had been identified previously as valid $\gamma$ protein interactors in brain, including MAP1A, PSD-95, synapse-associated protein 102 (SAP102), and PIST (Dakoji et al., 2003; Cuadra et al., 2004; Ives et al., 2004). These four proteins represented de facto positive controls, suggesting that our screen had been effective at finding true $\gamma$ interactors and increasing the likelihood that the novel prey we isolated would also be valid.

Two of the novel prey we identified were of particular interest to us for additional evaluation. MAGI-2 and MAGI-3 are multiPDZ domain-containing proteins that belong to the membraneassociated guanylate kinase with inverted domain organization (MAGI) family of scaffolding proteins. Although the fragments of MAGI-2 and MAGI-3 that we identified as prey in the primary yeast two-hybrid screen were detected by interaction with the $\gamma 2$ bait probe, secondary yeast cotransformation tests indicated that the MAGI-2 prey could also bind with the $\gamma 3$ and $\gamma 4$ baits and the MAGI-3 prey could also bind with the $\gamma 4$ and $\gamma 8$ baits (Table 1 ). The rationale for prioritizing these prey for additional analyses was based on three factors: the ability of both MAGI prey to bind with multiple different $\gamma$ protein baits, the observation that these interactions were limited specifically to the TARP subset of the $\gamma$ proteins ( $\gamma 2 \gamma 3, \gamma 4$, and $\gamma 8$ ), and the fact that MAGI-2 and MAGI-3 are PDZ domain proteins similar to multiple other previously confirmed $\gamma$ interacting proteins (PSD-95, PIST, and SAP102). Because MAGI-2 was inferred to bind the $\gamma$ protein baits with greater affinity than MAGI-3 in the cotransformation tests and MAGI-2 is expressed in brain at much higher levels than MAGI-3, we focused on evaluating MAGI-2 as a candidate TARP interactor in the current study.

\section{Expression of MAGI-2 and TARPs in mouse brain}

If the putative MAGI-2/TARP interactions identified by the yeast two-hybrid screens occur in vivo, these genes must be spatiotemporally coexpressed in brain. A detailed study of the developmental expression patterns of all eight Cacng genes in wild-type mouse brain was reported recently (Fukaya et al., 2005) and so was not required here. However, we did confirm by in situ hy- bridization that the mRNA expression of the TARP genes Cacng3, Cacng4, and Cacng8 was not qualitatively altered by the Cacng2 mutation in stargazer adult mouse brain, because we intended to use that tissue as a control in our experiments (supplemental Fig. 1, available at www.jneurosci.org as supplemental material).

We transfected full-length mouse $\gamma 2, \gamma 3, \gamma 4$, and $\gamma 8$ expression constructs into cultured HEK-293T cells and performed immunoblot analysis on crude cell lysates and membrane fractions to test the ability of a polyclonal anti-TARP antibody to recognize each of these proteins. This commercial antibody was raised against a C-terminal $\gamma 2$ antigen that is partially conserved (Fig. $1 B$ ) among all four TARPs and recognizes each of these proteins (Fig. 2). As expected from the amino acid alignments, the antiTARP antibody recognized $\gamma 2$ with the highest affinity and the other TARPS with lower affinities. Whereas immunoreactive bands corresponding to $\gamma 2, \gamma 3$, and $\gamma 4$ were close to the expected sizes of these proteins based on primary amino acid sequences $(323,315$, and 327 aa, respectively), the $\gamma 8$ specific band was smaller than predicted given its larger amino acid length of 423 aa. Identical results were obtained by Inamura et al. (2006), who expressed $\gamma 2$ and $\gamma 8$ in HEK-293T cells and examined their sizes by immunoblotting with antibodies different from the antiTARP antibody we used here. In that study, the apparent size discrepancy was interpreted as a likely difference in glycosylation between $\gamma 2$ and $\gamma 8$ in this cell line. The amount of immunoreactive protein contained in large-molecular-weight aggregates demonstrates that the $\gamma$ proteins are relatively insoluble under the mild extraction conditions often required to examine protein-protein interactions in vivo.

MAGI-2 is expressed exclusively in brain in three prominent isoforms $(\alpha, \beta$, and $\gamma$ ) (Hirao et al., 1998, 2000), but the distribution of these isoforms among major brain subdivisions is unknown. We used immunoblot analysis to examine the expression of MAGI-2 protein in cerebral cortex, cerebellum, and hippocampus in both wild-type and stargazer mouse brain using an antibody that recognizes all three isoforms (Fig. 3). In these tissues, MAGI- $2 \alpha$ and $\gamma$ expression were most prominent in cerebellum, which did not exhibit any detectable MAGI-2 $\beta$. Conversely, MAGI-2 $\beta$ was the most prominent isoform in cerebral cortex and hippocampus, which each expressed lower levels of MAGI- $2 \alpha$ and $\gamma$. An examination of mouse genomic sequences from NCBI databases corresponding to MAGI-2 revealed that the $\alpha, \beta$, and $\gamma$ isoforms each initiate translation from methionine start codons on distinct exons (exons 1, 2, and 4, respectively), suggesting that the $\beta$ and $\gamma$ isoforms result from the use of alternate transcriptional promoters in the preceding introns, which 


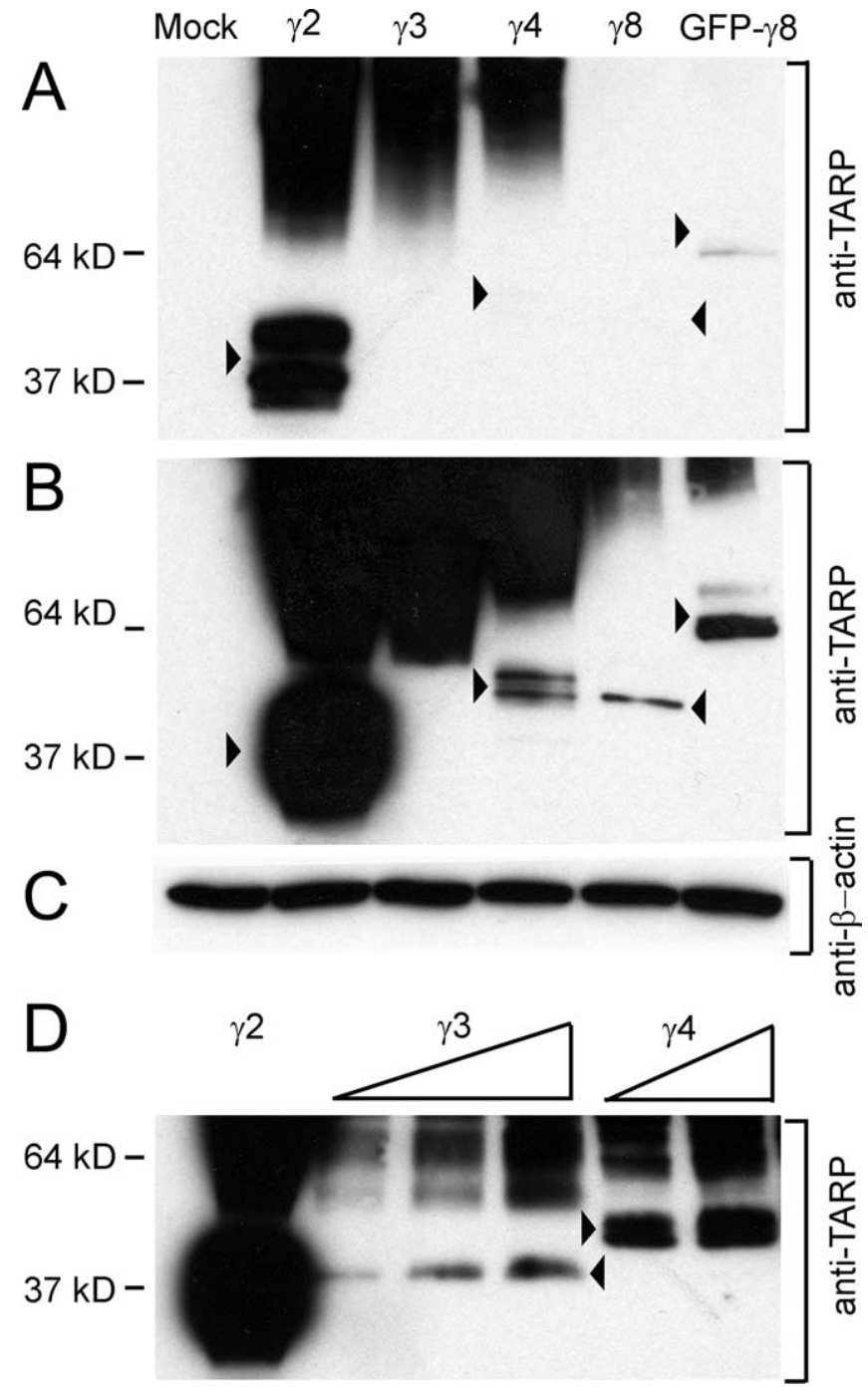

Figure 2. Recognition of a conserved $\gamma 2, \gamma 3, \gamma 4$, and $\gamma 8$ epitope by anti-TARP antibody. Crude lysates $(\boldsymbol{A}-\boldsymbol{C})$ or membrane fraction proteins $(\boldsymbol{D})$ were prepared from HEK293T cells transiently expressing $\gamma 2, \gamma 3, \gamma 4, \gamma 8$, or a GFP- $\gamma 8$ fusion protein and used for immunoblotting with polyclonal antibodies directed against C-terminal amino acids $305-$ 323 of the $\gamma 2$ protein (KDSKDSLHANTANRRTTPV). This antigen is partially conserved among all four TARPs (see Fig. $1 B$ ), resulting in an antibody that reacts strongly with $\gamma 2$ protein and moderately with $\gamma 3, \gamma 4$, and $\gamma 8$. A, A short exposure shows that anti-TARP antibodies effectively recognized a $\gamma 2$ doublet of the expected size, although much of the protein appeared to be trapped in insoluble aggregates near the top of the gel. $\boldsymbol{B}$, A longer exposure of the same immunoblot shows the antibody also detected $\gamma 4, \gamma 8$, and GFP $-\gamma 8$ proteins of the expected sizes. The $\gamma 3$ protein from cell lysate appeared to be highly insoluble. The arrows in $\boldsymbol{A}$ and $\boldsymbol{B}$ are identical to facilitate comparison. $\boldsymbol{C}$, The anti- $\beta$-actin immunoblot demonstrates equal sample loading in $\boldsymbol{A}$ and $\boldsymbol{B}$. $\boldsymbol{D}$, Membrane proteins were prepared from HEK-293T cells expressing either $\gamma 2, \gamma 3$, or $\gamma 4$ using the Cellytic MEM Protein kit (CE0050; Sigma) and immunoblotted with anti-TARP. Increasing amounts of the $\gamma 3$ and $\gamma 4$ membrane fraction were loaded on the gel. Although an improved yield of soluble $\gamma 3$ or $\gamma 4$ protein was obtained from membrane fractions relative to crude lysates, substantial amounts remained insoluble. Double bands of the TARPs represent glycosylated and unglycosylated isoforms. Molecular mass markers are indicated at the left. The anti-TARP antibody did not react with endogenous HEK-293T proteins (Mock).

are 387 and $140 \mathrm{kbp}$ in size (NCBI accession number NC_000071.3). No differences in the expression of any MAGI-2 isoforms were detected between wild type and stargazer in these brain regions.
A

MAGI-2 $\alpha$ 1-0 $\square=1-2+3-4-5-1277$

MAGI-2 $\beta$

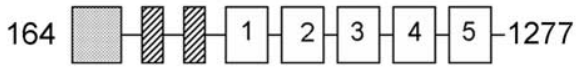

MAGI-2 $\gamma$

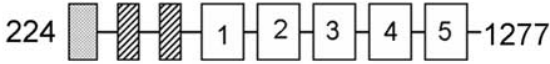

Yeast 2-Hybrid MAGI-2 prey
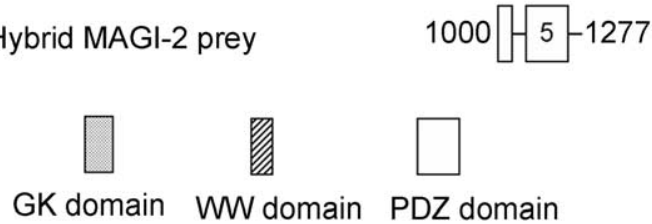

B

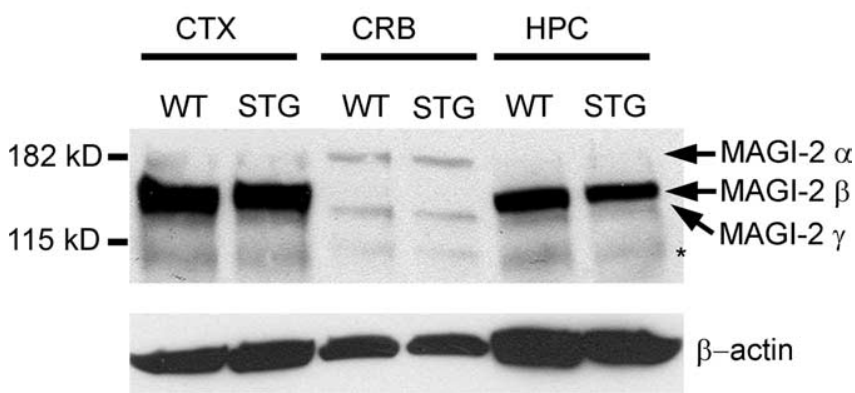

Figure 3. Differential expression of MAGI-2 isoforms in brain. $A$, Three distinct isoforms of MAGI-2 $(\alpha, \beta$, and $\gamma$ ) have been described previously (Hirao et al., 2000). The fragment of MAGI-2 that we identified by yeast two-hybrid screening contains 277 C-terminal amino acids that are present in all major MAGI-2 isoforms and encodes the last 10 amino acids of the PDZ4 domain and all of the PDZ5 domain. The numbers flanking each model indicate the first and last amino acids of each native isoform and the prey clone relative to the largest known isoform (MAGI-2 $\alpha$ ). GK, Guanylate kinase. B, Homogenates of cerebral cortex (CTX), cerebellum (CRB), and hippocampus (HPC) from adult wild-type (WT) and $\gamma 2$-null homozygous stargazer (STG) mice were used for immunoblot analysis with either anti-MAGI-2 (at 1:500; M2441; Sigma) or anti- $\beta$-actin (at 1:5000; A5316; Sigma). Anti-MAGI-2 recognized the expected MAGI-2 isoforms of $180(\alpha), 160(\beta)$, and $140(\gamma) \mathrm{kDa}$ (arrows). The smaller band of $105 \mathrm{kDa}$ (asterisk) recognized by this antibody may correspond to a yet undescribed MAGI- 2 isoform. The anti- $\beta$ actin immunostaining shows the relative protein loading from each brain region on the blot.

\section{Coimmunoprecipitation of MAGI-2 and TARPs from mouse brain}

We performed coimmunoprecipitation experiments to test whether TARPs interacted with MAGI-2 in vivo in mouse brain (Fig. 4). The anti-TARP antibody coimmunoprecipitated with two prominent MAGI-2 isoforms from wild-type and stargazer cerebral cortex but not from cerebellum or hippocampus from either mouse. These isoforms correspond to MAGI- $2 \alpha$ and $\beta$ based on their sizes. In wild-type cerebral cortex, $\gamma 2, \gamma 3$, and $\gamma 8$ were also immunoprecipitated so any of these, or some combination, might be responsible for interacting with MAGI-2. In $\gamma 2$-null stargazer cerebral cortex, only $\gamma 3$ and $\gamma 8$ were immunoprecipitated, indicating that one or both of these proteins interacted with MAGI-2 in vivo. Although $\gamma 2$ was immunoprecipitated from wild-type cerebellum and hippocampus, MAGI-2 was not coimmunoprecipitated from these brain regions at detectable levels.

\section{PDZ domain interactions between stargazin and MAGI-2}

To further characterize protein-protein interactions between the TARPs and MAGI-2, we performed in vitro binding assays using 

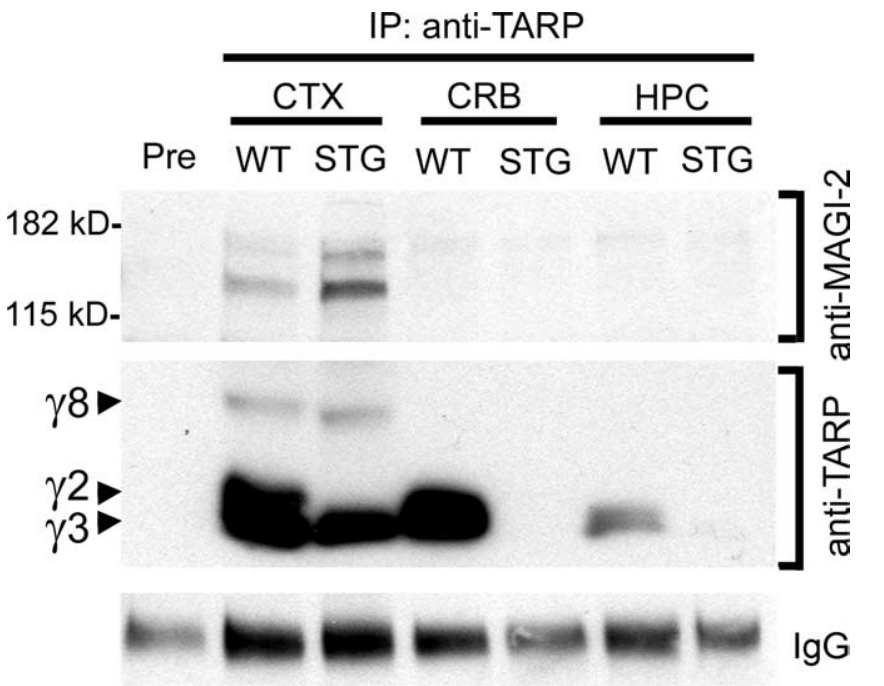

$\lg G$

Figure 4. MAGI-2 interacts with TARPs in mouse cerebral cortex. Homogenates of cerebral cortex (CTX), cerebellum (CRB), and hippocampus (HPC) from wild-type (WT) and $\gamma 2$-null stargazer (STG) mouse brain were used for immunoprecipitation with the anti-TARP antibody (IP: anti-TARP; $5 \mu \mathrm{g}$ /reaction). Immunoprecipitated proteins were separated on a $4-20 \%$ SDSPAGE gel for immunoblot analysis with either anti-MAGI-2 (1:500) or anti-TARP $(1 \mu \mathrm{g} / \mu \mathrm{l})$ antibodies. The anti-MAGI-2 blot shows that anti-TARP coimmunoprecipitated MAGI-2 from both wild-type and stargazer cerebral cortex but not from cerebellum or hippocampus. The anti-TARP blot shows that anti-TARP immunoprecipitated $\gamma 2, \gamma 3$, and $\gamma 8$ from wild-type cortex but only $\gamma 3$ and $\gamma 8$ from stargazer cerebral cortex. The anti-TARP antibody immunoprecipitated detectable amounts of $\gamma 2$ only from wild-type cerebellum and hippocampus. The lgG panel shows that equal amounts of preimmune sera and anti-TARP sera were used for the immunoprecipitation reactions. The results shown were replicated in duplicate experiments.

$\gamma 2$ protein and fragments of MAGI-2 fused to GST (Fig. 5). The GST fusion protein containing only the guanylate kinase domain and WW domains of MAGI- 2 was unable to bind $\gamma 2$. However, GST fused to full-length MAGI-2, MAGI-2 PDZ domains 1-5, or MAGI-2 PDZ domains $1-3$ did bind $\gamma 2$. These results suggest that one or more of the PDZ domains mediate basic $\gamma 2$ binding and that the GK and WW domains are not necessary for this function. The three GST-MAGI-2 fusion proteins each bound three distinct $\gamma 2$ immunoreactive bands, presumably representing different posttranslational modifications of $\gamma 2$ as it was expressed in HEK-293T cells (Fig. 5B). The smaller $\gamma 2$ bands were identical in size. However, the largest $\gamma 2$ band retained from interactions with full-length MAGI-2 was slightly larger than the largest $\gamma 2$ band retained by interactions with the PDZ domain $1-5$ or 1-3 GST fusions, suggesting that some posttranslational control over $\gamma 2$-Magi-2 binding selectivity is possible.

We generated fusion proteins of GST with each of the five MAGI-2 PDZ domains to determine which was responsible for binding $\gamma 2$ in vitro. For this experiment, we used only the C-terminal 121 aa of $\gamma 2$ linked to $\mathrm{N}$-terminal $\mathrm{His}_{6}$ and c-myc epitopes to facilitate purification. The results showed that PDZ domains 1,3 , and 5, but not PDZ domains 2 and 4 , bound to the cytoplasmic $\gamma 2 \mathrm{C}$-terminal domain (Fig. 6A,B). PDZ1 appeared to exhibit the strongest affinity and PDZ5 the weakest. A subsequent multiple sequence alignment and phylogenetic reconstruction showed that PDZ domains 1, 3, and 5 of MAGI-2 were most similar to each other and were distinct from PDZ domains 2 and 4 , consistent with the preferential binding pattern observed (supplemental Fig. 2, available at www.jneurosci.org as supplemental material). Because many subclasses of PDZ domains typically interact with only the C-terminal few amino acids of their ligand proteins, we tested whether this was also true for the $\gamma 2-$ MAGI-2
A

MAGI-2 $\beta$

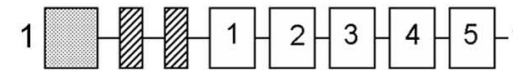

$-1112$

1. GST

2. GST-MAGI-2

3. GST-GKW

4. GST-PDZ 1-5

5. GST-PDZ 1-3
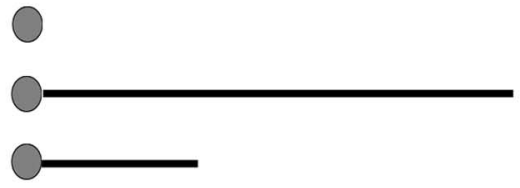

B
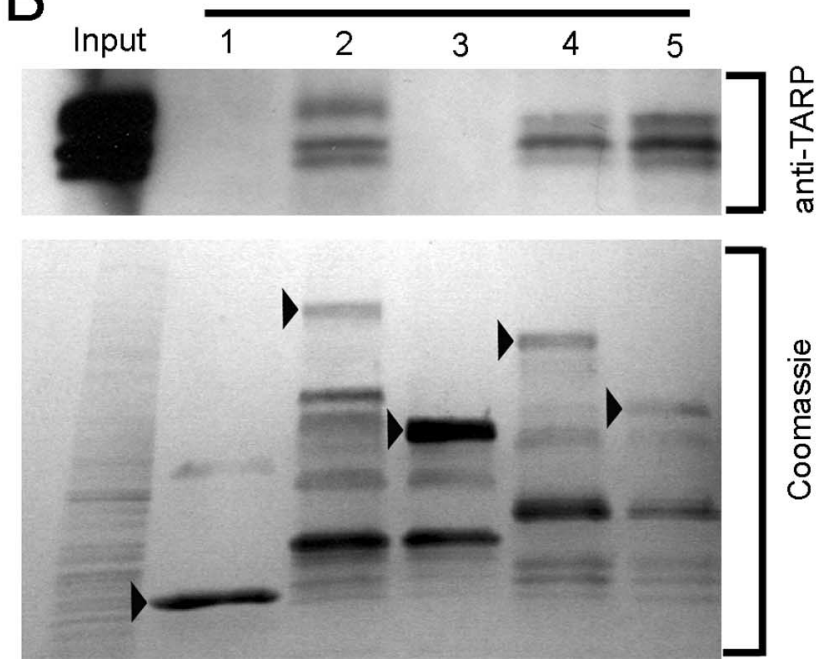

Figure 5. The PDZ domains of MAGI- 2 are required for $\gamma 2$ interaction in vitro. $A$, The molecular organization of MAGI-2 $\beta$ and derivative GST-MAGI-2 fusion proteins used in the experiment (1-5) is illustrated. $\boldsymbol{B}$, Proteins corresponding to GST or GST fused to various MAGI-2 $\beta$ fragments were immobilized on glutathione-Sepharose beads and incubated with membrane proteins prepared from HEK-293T cells expressing $\gamma 2$. Bound protein complexes were analyzed by SDS-PAGE and immunoblotted with anti-TARP antibody. The numbers of the GST or GSTMAGI-2 fusion proteins in $\boldsymbol{A}$ correspond to numbered lanes in $\boldsymbol{B}$. Coomassie blue staining of the original gel shows the relative amount, purity, and expected size (arrows) of GST or GSTMAGI-2 fusion proteins. The smaller Coomassie blue-stained fragments in each lane represent partial proteolytic products. The anti-TARP immunoblot shows that GST fusion proteins containing full-length MAGI-2, PDZ1-5, or PDZ1-3 were able to bind $\gamma 2$ protein effectively, whereas GST alone or the GST-GKW fusion protein did not. The existence of multiple anti-TARP immunoreactive bands likely reflects differential posttranslational modifications (glycosylation and phosphorylation) of the $\gamma 2$ protein. Whereas the GST-MAGI-2 fusion proteins in lanes 2, 4, and 5 each interacted with three distinct $\gamma 2$ bands, the largest $\gamma 2$ band bound by full-length MAGI-2 (lane 2) was different in size than the largest $\gamma 2$ bands bound by the MAGI-2 PDZ domains (lanes 4, 5). The Input lane contains membrane protein prepared from HEK-293T cells expressing $\gamma 2$ before incubation with GST fusion proteins. The results shown are representative of duplicate experiments.

interaction. We repeated the experiments using a recombinant $\gamma 2$ protein missing the final four amino acids (-TTPV) and showed that this alteration obliterated binding to the MAGI-2 PDZ domains (Fig. 6C,D). The observation that these four C-terminal amino acids are perfectly conserved among all TARP proteins $(\gamma 2, \gamma 3, \gamma 4$ and $\gamma 8)$ (Fig. $1 B)$ raises the possibility that MAGI-2 could interact with each TARP in vivo via the same PDZ domains and a similar binding mechanism.

\section{Stargazin recruits MAGI-2 to cell membranes}

Protein interactions characterized in vitro may not be representative of interactions between the same molecules in the more 


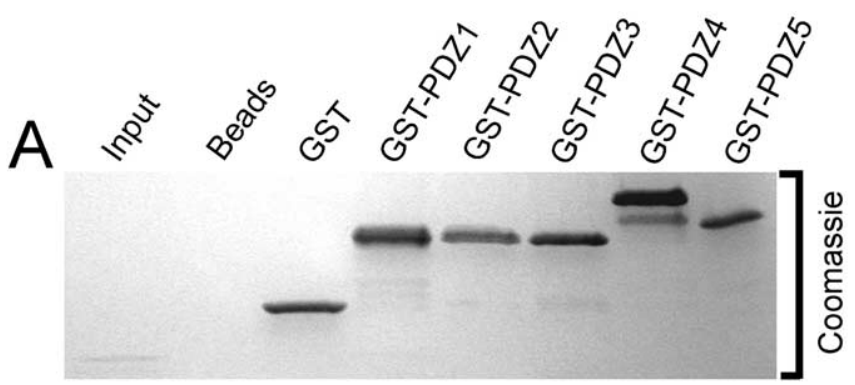

B

His $_{6}$-myc-Cacng2 (204-323 aa)

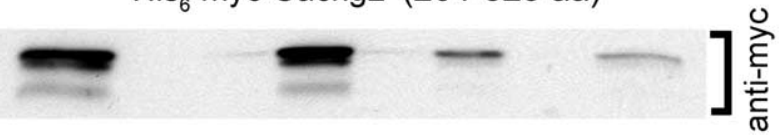

C

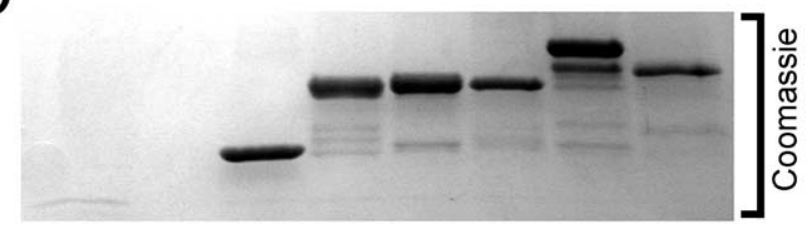

D

His - -myc-Cacng2 $\triangle$ TTPV (204-319 aa)

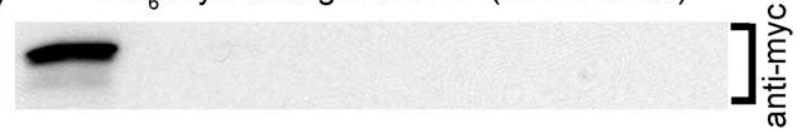

Figure 6. The C-terminal-TTPV motif of $\gamma 2$ is a ligand for PDZ domains 1,3 , and 5 of MAGI-2 in vitro. GST or GST fusion proteins of PDZ1, PDZ2, PDZ3, PDZ4, or PDZ5 were immobilized on glutathione-Sepharose beads and incubated with either $\mathrm{His}_{6}-$ myc $-\gamma 2$ (amino acids $204-323$ ) $(\boldsymbol{A}, \boldsymbol{B})$ or $\mathrm{His}_{6}-\mathrm{myc}-\gamma 2 \Delta$ TTPV (amino acids 204-319) (C, D). Bound protein complexes were analyzed by SDS-PAGE and immunoblotted with anti-myc antibodies $(\boldsymbol{B}, \boldsymbol{D})$. Coomassie blue staining shows the relative amount and purity of the recombinant GST fusion proteins $(\boldsymbol{A}, \boldsymbol{C})$. The anti-myc blots show that GST fusion proteins with PDZ1, PDZ3, or PDZ5 pull down $\mathrm{His}_{6}-$ myc- $\gamma 2$ (amino acids 204-323) effectively $(\boldsymbol{B})$ but do not pull down $\mathrm{His}_{6}-$ myc- $\gamma 2 \Delta$ TTPV (amino acids 204-319) (D). GST does not pull down either $\gamma 2$ or $\gamma 2 \Delta$ TTPV. Equal amounts of GST fusion proteins $(\sim 2 \mu \mathrm{g} / \mu \mathrm{l})$ were used for the pull-down assays $(\boldsymbol{A}, \boldsymbol{C})$. Input was purified $\mathrm{His}_{6}-$ myc $-\gamma 2$ (amino acids 204-323) $(\boldsymbol{A}, \boldsymbol{B})$ or $\mathrm{His}_{6}-$ myc $-\gamma 2 \Delta$ TTPV (amino acids 204-319) $(\boldsymbol{C}, \boldsymbol{D})$ before incubation with GST or GST fusion proteins. The results shown are representative of duplicate experiments.

complex cellular environment. To test this for $\gamma 2-$ MAGI-2, we expressed three fluorescently tagged fusion proteins in cultured HEK-293T cells: MAGI-2 (GFP-MAGI-2), $\gamma 2$ (HcRed-Cacng2), and $\gamma 2$ minus the conserved C-terminal PDZ interaction motif (HcRed-Cacng2 $\Delta$ TTPV) (Fig. 7). When expressed alone, HcRed-Cacng2 and HcRed-Cacng2 $\Delta$ TTPV were each localized to plasma membranes with the highest levels observed at points of cell-cell contact. GFP-MAGI-2, expressed alone, exhibited a diffuse localization throughout the cytoplasm. The coexpression of GFP-MAGI-2 with HcRed-Cacng2 $\Delta$ TTPV did not appreciably alter the cellular distribution of either molecule, consistent with the requirement of the $\gamma 2$-TTPV motif for binding between these molecules. Coexpression of GFP-MAGI-2 with HcRedCacng2, however, dramatically altered the distribution of both molecules. In these cells, GFP-MAGI-2 was recruited to the plasma membrane in which it overlapped closely with HcRedCacng2, whereas HcRed-Cacng2 exhibited a more punctate and membrane-specific pattern than when it was expressed in the absence of GFP-MAGI-2. These cellular data are consistent with the results of the yeast two-hybrid in vitro binding and in vivo coimmunoprecipitation results and support a physical interaction between MAGI-2 and Cacng2.

\section{Discussion}

Our experiments indicate that stargazin $\left(\gamma_{2}\right)$ and other TARPs interact with the multi-PDZ domain synaptic scaffolding protein MAGI-2 (S-SCAM) in mouse brain. This interaction was initially suggested by yeast two-hybrid screening experiments and was subsequently confirmed by in vitro binding assays, in vivo coimmunoprecipitation, and reciprocal alteration of $\gamma 2$ and MAGI-2 subcellular localization after coexpression in cultured cells. We also determined that the $\gamma 2 \mathrm{C}$-terminal -TTPV amino acid motif, which is shared by all four TARPs $(\gamma 2, \gamma 3, \gamma 4$, and $\gamma 8)$, interacted specifically with PDZ domains 1,3 , and 5 of MAGI-2 but not with PDZ domains 2 and 4. These findings identify MAGI-2 as a candidate for physically linking TARP/AMPAR complexes to a wide range of other postsynaptic molecules and define an important new node among protein interactions at the vertebrate synapse.

\section{Regional specificity of TARP-MAGI-2 interactions in brain}

Several factors likely influence which TARPs interact with MAGI-2 in particular brain regions, including coexpression, competition, and posttranslational modification. The fundamental importance of coexpression is shown by the result that anti-TARP antibodies immunoprecipitated detectable amounts of MAGI-2 from adult mouse cerebral cortex (high MAGI-2 levels) but not from cerebellum (very low MAGI-2 levels), although both tissues expressed a similar amount of TARPs. Ultimately, an analysis of the coexpression of MAGI-2 and TARPs in individual cells, using high-resolution in situ or laser microdissection approaches, will be required to determine which specific TARPMAGI-2 interactions are possible in a particular cell type.

Competition for protein binding sites may influence TARPMAGI-2 interactions in two general ways: competition between different PDZ domain proteins for binding to the same TARP and competition between different TARPs (and other proteins) for binding to the same PDZ domain protein. In the first case, it was reported previously that TARPs associate with the MAGUK proteins PSD-95 and PSD-93 in brain (Dakoji et al., 2003). Here we show that the same TARPs associate with MAGI-2 in brain. Because PSD-95, PSD-93, and MAGI-2 each bind the same C-terminal -TTPV motif, competition between coexpressed PDZ proteins for binding to TARPs is likely. The significance of this competition remains to be explored. Regarding the second type of competition, we determined that $\gamma 2$ could bind PDZ domains 1,3 , and 5 of MAGI-2 with an apparent preference for PDZ domain 1. If other TARPs exhibit similar binding affinities, which we suspect, there could be competition among the TARPs for access to individual MAGI-2 PDZ domains. Additional competition could come from the many other known MAGI-2 interactors. For example, four neuroligin proteins (Nlgn1-Nlgn4) each terminate with the PDZ binding amino acid motif-TTRV, which is quite similar to the terminal motif of the TARPs (-TTPV) because position -1 is considered of minor importance for PDZ binding specificity (van Ham and Hendriks, 2003). Neuroligins are clustered by MAGI-2 (Iida et al., 2004), and the C terminus of neuroligin-1 interacts specifically with PDZ domain 1 (Hirao et al., 1998). Other proteins interacting with PDZ domain 1 include the $\beta 1$-adrenergic receptor ( $\mathrm{Xu}$ et al., 2001) and neural GDP/ GTP exchange protein Rapgef2 (Ohtsuka et al., 1999). Measuring the relative access of TARPs and other proteins to different PDZ domains of MAGI-2 in vivo will be an important topic of future investigation.

Posttranslational modification of TARPs is another logical mechanism for regulating MAGI-2 interactions in vivo. For example, PKA phosphorylation of a threonine residue (T321) in the 
-TTPV motif of $\gamma 2$ disrupts binding by PSD-95 (Chetkovich et al., 2002; Choi et al., 2002). Thus, phosphorylation by PKA or other kinases is a reasonable candidate for regulating the synaptic targeting of $\gamma 2$ and associated AMPARs by other PDZ proteins in vivo, including MAGI-2. Interestingly, a recent study suggests that phosphorylation of $\gamma 2$ and $\gamma 8$ by different sets of kinases and phosphatases in cortical neurons may regulate the association of these TARPs with different PDZ proteins and their localization to biochemically distinct membrane compartments (Inamura et al., 2006). A role for PKC phosphorylation in controlling the binding of MAGI-2 PDZ domains to other ligands has been documented (Yap et al., 2003), but the regulation of TARP-MAGI-2 interactions by similar posttranslational modifications remains to be tested.

\section{A role for MAGI-2 ligands in the AMPA receptor pathway?}

TARPs bind AMPAR subunits in vivo and are increasingly recognized as critical regulators of AMPAR trafficking and biophysical properties in neurons (Nicoll et al., 2006). The significance of this relationship is highlighted by the fact that mutations in the Cacng2 gene result in AMPAR dysfunction associated with severe epilepsy and ataxia in stargazer mice (Letts et al., 1998), and targeted inactivation of the mouse $\gamma 8$ gene (Cacng8) alters hippocampal AMPAR distribution and synaptic plasticity (Rouach et al., 2005). Previous studies of MAGI-2 revealed interactions with a large and diverse array of interesting brain proteins. An important outcome of our current study, which indicates that TARPs might act as a physical link between AMPARs and MAGI-2, will be the promotion of some of these MAGI-2 ligands as plausible candidates for involvement in the AMPAR signaling pathway.

Perhaps most exciting is the recent discovery that synaptic clustering of NMDA receptors in cultured ventral spinal neurons and hippocampal interneurons is dependent on the presence of synaptic AMPA receptors and that the synaptic AMPA and NMDA receptors are physically linked by stargazin and some unidentified PDZ protein (Mi et al., 2004). Hirao et al. $(1998,2000)$ demonstrated that PDZ domain 5 of MAGI-2 interacted with the NMDA receptor subunits $2 \mathrm{~A}$ and $2 \mathrm{C}$.

Consequently, our demonstration that stargazin binds PDZ domain 1 of MAGI-2 suggests that MAGI-2 could be the missing link between synaptic AMPA and NMDA receptors. Other known MAGI-2 ligands that might be associated with the AMPA receptor pathway via TARP-MAGI-2 interactions include the

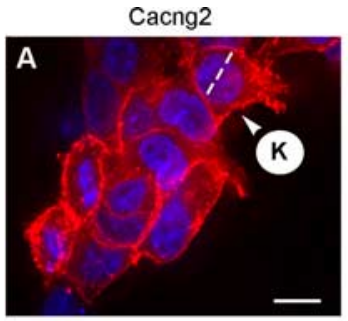

Cacng2

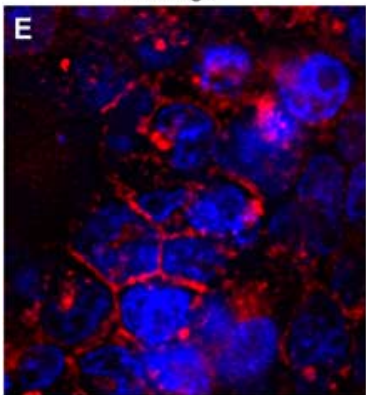

Cacng2 $\Delta$ TTPV
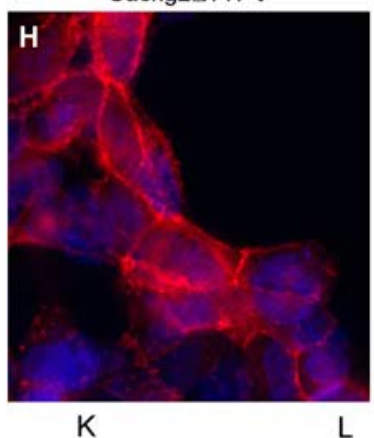

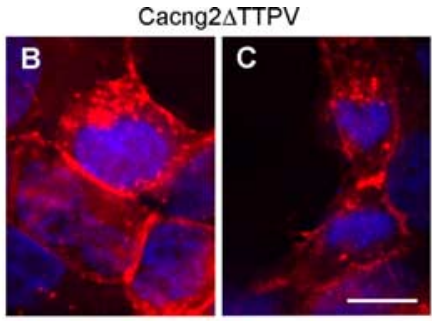

MAGI-2

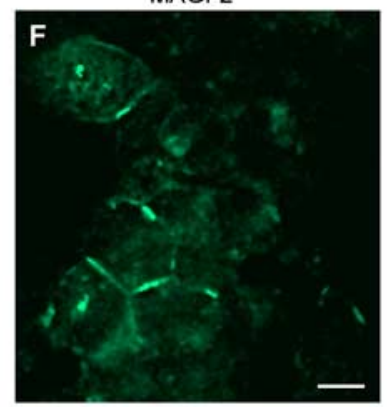

MAGI-2

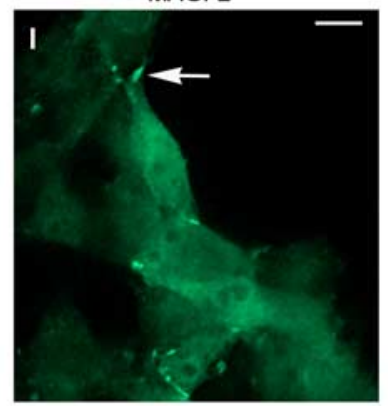

M

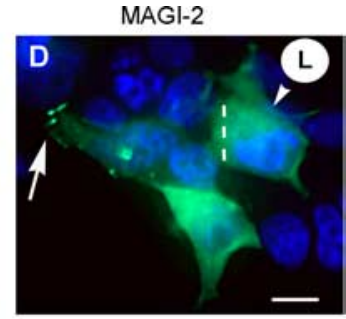

Merge

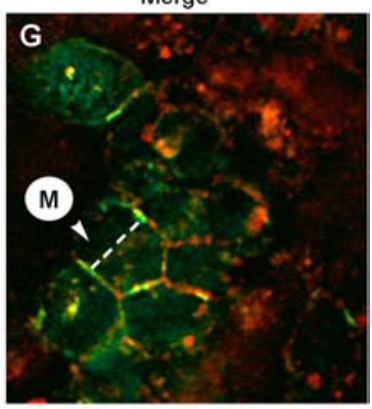

Merge

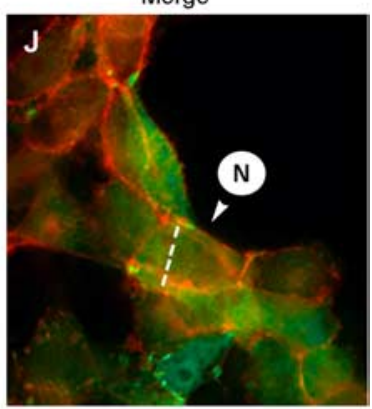

$\mathrm{N}$

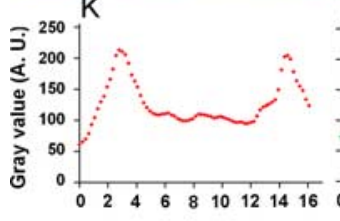

M

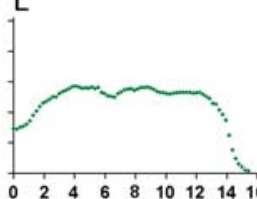

Position across cell $(\mu \mathrm{m})$

Figure 7. Recruitment of MAGl-2 to plasma membranes requires the C-terminal -TTPV motif of $\gamma 2$. Deconvolution micrographs are shown of HEK-293T cells transiently transfected for expression of HcRed wild-type Cacng2 ( $\gamma 2)$, HcRedCacng2 $\Delta$ TTPV, or GFP-MAGI-2 fusion proteins, individually $(\boldsymbol{A}-\boldsymbol{D})$ or in combinations $(\boldsymbol{E}-\boldsymbol{J})$. Nuclei are stained with DAPI (blue). Cacng 2 is membrane-associated and concentrated at cell-cell contact sites in the presence $(\boldsymbol{A})$ or absence $(\boldsymbol{B}, \boldsymbol{C})$ of the $\boldsymbol{C}$-terminal -TTPV amino acid motif. MAGI-2 expressed alone $(\boldsymbol{D})$ is generally diffuse throughout the cytoplasm and only occasionally concentrated near membranes (arrow). $\boldsymbol{E}-\boldsymbol{G}$ show cells cotransfected with HcRed-Cacng2 and GFP-MAGI-2 and visualized for HcRedCacng2 $(\boldsymbol{E})$, GFP-MAGI-2 $(\boldsymbol{F})$, or both images merged $(\boldsymbol{G})$. $\boldsymbol{H}-\boldsymbol{J}$ show cells cotransfected with HcRed-Cacng2 $\Delta$ TTPV and GFPMAGI-2 and visualized for HcRed-Cacng2 $\Delta$ TTPV $(\boldsymbol{H})$, GFP-MAGI-2 $(\boldsymbol{I})$, or both images merged $(\boldsymbol{J})$. Efficient recruitment of MAGI-2 to plasma membranes requires the C-terminal -TTPV motif of $\gamma 2$, which we showed is a binding target for PDZ domains 1, and, 5 of MAGI-2 $(\boldsymbol{F}, \boldsymbol{I})$. Wild-type Cacng2 expressed alone $(\boldsymbol{A})$ exhibits a membrane localization similar to mutant Cacng2 $\triangle$ TTPV coexpressed with MAGI-2 $(\boldsymbol{H})$. However, when wild-type Cacng2 is coexpressed with MAGI-2 (E), Cacng2 localization in the membrane appeared more concentrated and punctate than when Cacng2 was expressed alone, suggesting clustering of Cacng2 by the multi-PDZ domain MAGI-2 protein. The circled letters $\boldsymbol{K}$-- $\boldsymbol{N}$ in $\boldsymbol{A}, \boldsymbol{D}, \mathbf{G}$, and $\boldsymbol{J}$ indicate the positions of 3-pixel-wide digital transects (dashed lines) corresponding to fluorescence intensity measured across representative cells shown in $\boldsymbol{K}$-- $\boldsymbol{N}$ $(0-255$ in grayscale arbitrary units, A.U.). $\boldsymbol{K}, \mathrm{HcRed}-$ Cacng2 expressed alone is concentrated at cell membranes. $L, G F P-M A G I-2$ expressed alone appears diffuse in the cytoplasm. $\boldsymbol{M}$, When $\mathrm{HcRed-Cacng} 2$ is coexpressed with GFP-MAGI-2, the fluorescence intensity transects overlap and both are concentrated at cell membranes. $\boldsymbol{N}$, When HcRed-Cacng $2 \Delta$ TTPV is coexpressed with GFP-MAGI-2, the fluorescence intensity transects do not overlap; HcRed-Cacng2 $\Delta$ TTPV is concentrated at cell membranes, but GFP-MAGI-2 is not recruited to plasma membranes. Scale bars, $10 \mu \mathrm{m}$.

following: atrophin-1, activin receptor- $2 \mathrm{~A}$, axin, $\beta 1$-adrenergic receptors, $\beta$ - and $\delta$-catenin, Cnksr2 (connector enhancer of kinase suppressor of Ras 2)/Maguin-1, dasm1 (dendrite arborization and synapse maturation 1$), \delta$-1/Dll1 (delta-like 1 ), dendrin, hyperpolarization-activated cation channel 2, neuroligins, PTEN 
(phosphatase and tensin homolog), RapGEF2 (Rap guanine nucleotide exchange factor 1), and SAP-associated protein (Hirao et al., 1998; Wood et al., 1998; Ide et al., 1999; Ohtsuka et al., 1999; Yao et al., 1999; Shoji et al., 2000; Wu et al., 2000; Xu et al., 2001; Nishimura et al., 2002; Pfister et al., 2003; Hirabayashi et al., 2004; Iida et al., 2004; Kimura et al., 2004; Shi et al., 2004; Kremerskothen et al., 2006).

\section{MAGI-2 and neuronal cell adhesion}

Although the reliance of the glutamate signaling pathway on PDZ protein interactions at synapses is well documented, an important association with cell adhesion molecules is now emerging. NMDA receptors, for example, are linked to the synaptic adhesion protein neuroligin through the PDZ protein PDS-95 and were recently discovered to also interact with a novel family of PDZ domain-containing proteins called synaptic adhesion-like molecules, or SALMs (Wang et al., 2006). Our identification of interactions between the AMPA receptor regulating TARPs and the PDZ protein MAGI-2 expands on this concept.

Neuronal synapses have much in common with the intercellular adhesive junctions formed by other cell types (Yamagata et al., 2003). We recently reported that TARPs are evolutionarily related to a large family of proteins known as claudins, which regulate cell adhesion and paracellular permeability as fundamental components of non-neuronal tight junctions (Price et al., 2005). In that study, we showed that expression of stargazin in cultured fibroblasts results in cell aggregation similar to that produced by claudins. We speculated that stargazin and other TARPs might act as cell-cell adhesion molecules at neuronal adhesive junctions in vivo, reminiscent of the role of claudins at classical tight junctions. Our identification of the TARP-MAGI-2 interaction supports and extends that hypothesis. First, MAGI-1 and MAGI-3, which are paralogs of MAGI-2, serve as scaffolding proteins at epithelial cell tight junctions in which they colocalize with claudins, which are paralogs of TARPs (Ide et al., 1999; Mino et al., 2000; Wu et al., 2000; Yamada et al., 2004). Second, MAGI-2 was identified as a component of perisynaptic adherens junctions between mossy fiber terminals and the dendrites of CA3 pyramidal cells in mouse hippocampus, in which it interacts with the adhesion proteins $\beta$-catenin, nectin-1, and neuroligin (Yamada et al., 2003; Subauste et al., 2005). We predict that the TARPs will also be localized here through their association with MAGI-2. In fact, immunoelectron microscopic studies recently showed $\gamma 2$ and $\gamma 8$ situated at the edge of postsynaptic densities in asymmetrical synapses (Inamura et al., 2006), consistent with the location of some adherens junctions (Nishioka et al., 2000).

Together, these observations raise the intriguing possibility of a common ancestral origin for synaptic adherens junctions and epithelial tight junctions. Both structures serve as docking sites for numerous proteins that exploit the implicit proximity of adjoining cells to maximize their own signaling or structural functions. This similarity might be the product of convergent evolution or it could reflect divergence from a common origin. The presence of MAGI and TARP proteins at neuronal adherens junctions, and MAGI and claudin proteins at epithelial tight junctions, would support a common origin. It is relevant to note that both neurons and epithelial cells are ultimately derived from the same simple ectoderm during early embryonic development. It will be exciting to discover whether this emerging paralogous relationship between neuronal and non-neuronal adhesive cell junctions will be found to encompass additional molecules.

\section{References}

Abramoff MD, Magelhaes PJ, Ram SJ (2004) Image processing with ImageJ. Biophoton Int 11:36-42.

Black III JL, Lennon VA (1999) Identification and cloning of putative human neuronal voltage-gated calcium channel $\gamma 2$ and $\gamma 3$ subunits: neurologic implications. Mayo Clin Proc 74:357-361.

Burgess DL, Davis CF, Gefrides LA, Noebels JL (1999) Identification of three novel $\mathrm{Ca}^{2+}$ channel $\gamma$ subunit genes reveals molecular diversification by tandem and chromosome duplication. Genome Res 9:1204-1213.

Burgess DL, Gefrides LA, Foreman PJ, Noebels JL (2001) A cluster of three novel $\mathrm{Ca}^{2+}$ channel $\gamma$ subunit genes on chromosome 19q13.4: evolution and expression profile of the $\gamma$ subunit gene family. Genomics 71:339-350.

Chen L, Chetkovich DM, Petralia RS, Sweeney NT, Kawasaki Y, Wenthold RJ, Bredt DS, Nicoll RA (2000) Stargazin regulates synaptic targeting of AMPA receptors by two distinct mechanisms. Nature 408:936-943.

Chetkovich DM, Chen L, Stocker TJ, Nicoll RA, Bredt DS (2002) Phosphorylation of the postsynaptic density-95 (PSD-95)/discs large/zona occludens- 1 binding site of stargazin regulates binding to PSD-95 and synaptic targeting of AMPA receptors. J Neurosci 22:5791-5796.

Choi J, Ko J, Park E, Lee JR, Yoon J, Lim S, Kim E (2002) Phosphorylation of stargazin by protein kinase A regulates its interaction with PSD-95. J Biol Chem 277:12359-12363.

Chu PJ, Robertson HM, Best PM (2001) Calcium channel gamma subunits provide insights into the evolution of this gene family. Gene 280:37-48.

Cuadra AE, Kuo SH, Kawasaki Y, Bredt DS, Chetkovich DM (2004) AMPA receptor synaptic targeting regulated by stargazin interactions with the Golgi-resident PDZ protein nPIST. J Neurosci 24:7491-7502.

Dakoji S, Tomita S, Karimzadegan S, Nicoll RA, Bredt DS (2003) Interaction of transmembrane AMPA receptor regulatory proteins with multiple membrane associated guanylate kinases. Neuropharmacology 45:849-856.

Fukaya M, Yamazaki M, Sakimura K, Watanabe M (2005) Spatial diversity in gene expression for VDCC $\gamma$ subunit family in developing and adult mouse brains. Neurosci Res 53:376-383.

Hashimoto K, Fukaya M, Qiao X, Sakimura K, Watanabe M, Kano M (1999) Impairment of AMPA receptor function in cerebellar granule cells of ataxic mutant mouse stargazer. J Neurosci 19:6027-6036.

Hirabayashi S, Nishimura W, Iida J, Kansaku A, Kishida S, Kikuchi A, Tanaka N, Hata Y (2004) Synaptic scaffolding molecule interacts with axin. J Neurochem 90:332-339.

Hirao K, Hata Y, Ide N, Takeuchi M, Irie M, Yao I, Deguchi M, Toyoda A, Sudhof TC, Takai Y (1998) A novel multiple PDZ domain-containing molecule interacting with $N$-methyl-D-aspartate receptors and neuronal cell adhesion proteins. J Biol Chem 273:21105-21110.

Hirao K, Hata Y, Yao I, Deguchi M, Kawabe H, Mizoguchi A, Takai Y (2000) Three isoforms of synaptic scaffolding molecule and their characterization. Multimerization between the isoforms and their interaction with $N$-methyl-D-aspartate receptors and SAP90/PSD-95-associated protein. J Biol Chem 275:2966-2972.

Ide N, Hata Y, Deguchi M, Hirao K, Yao I, Takai Y (1999) Interaction of S-SCAM with neural plakophilin-related Armadillo-repeat protein $/ \delta$ catenin. Biochem Biophys Res Commun 256:456-461.

Iida J, Hirabayashi S, Sato Y, Hata Y (2004) Synaptic scaffolding molecule is involved in the synaptic clustering of neuroligin. Mol Cell Neurosci 27:497-508.

Inamura M, Itakura M, Okamoto H, Hoka S, Mizoguchi A, Fukazawa Y, Shigemoto R, Yamamori S, Takahashi M (2006) Differential localization and regulation of stargazin-like protein, gamma- 8 and stargazin in the plasma membrane of hippocampal and cortical neurons. Neurosci Res 55:45-53.

Ives JH, Fung S, Tiwari P, Payne HL, Thompson CL (2004) Microtubuleassociated protein light chain 2 is a stargazin-AMPA receptor complexinteracting protein in vivo. J Biol Chem 279:31002-31009.

Kang MG, Chen CC, Felix R, Letts VA, Frankel WN, Mori Y, Campbell KP (2001) Biochemical and biophysical evidence for $\gamma$-2 subunit association with neuronal voltage-activated $\mathrm{Ca}^{2+}$ channels. J Biol Chem 276:32917-32924.

Kimura K, Kitano J, Nakajima Y, Nakanishi S (2004) Hyperpolarizationactivated, cyclic nucleotide-gated HCN2 cation channel forms a protein assembly with multiple neuronal scaffold proteins in distinct modes of protein-protein interaction. Genes Cells 9:631-640.

Kious BM, Baker CV, Bronner-Fraser M, Knecht AK (2002) Identification 
and characterization of a calcium channel $\gamma$ subunit expressed in differentiating neurons and myoblasts. Dev Biol 243:249-259.

Kremerskothen J, Kindler S, Finger I, Veltel S, Barnekow A (2006) Postsynaptic recruitment of Dendrin depends on both dendritic mRNA transport and synaptic anchoring. J Neurochem 96:1659-1666.

Letts VA, Felix R, Biddlecome GH, Arikkath J, Mahaffey CL, Valenzuela A, Bartlett 2nd FS, Mori Y, Campbell KP, Frankel WN (1998) The mouse stargazer gene encodes a neuronal $\mathrm{Ca}^{2+}$-channel $\gamma$ subunit. Nat Genet 19:340-347.

Mi R, Sia GM, Rosen K, Tang X, Moghekar A, Black JL, McEnery M, Huganir RL, O'Brien RJ (2004) AMPA receptor-dependent clustering of synaptic NMDA receptors is mediated by Stargazin and NR2A/B in spinal neurons and hippocampal interneurons. Neuron 44:335-349.

Mino A, Ohtsuka T, Inoue E, Takai Y (2000) Membrane-associated guanylate kinase with inverted orientation (MAGI)-1/brain angiogenesis inhibitor 1-associated protein (BAP1) as a scaffolding molecule for Rap small G protein GDP/GTP exchange protein at tight junctions. Genes Cells 5:1009-1016.

Moss FJ, Viard P, Davies A, Bertaso F, Page KM, Graham A, Canti C, Plumpton M, Plumpton C, Clare JJ, Dolphin AC (2002) The novel product of a five-exon stargazin-related gene abolishes $\mathrm{Ca}_{\mathrm{v}} 2.2$ calcium channel expression. EMBO J 21:1514-1523.

Moss FJ, Dolphin AC, Clare JJ (2003) Human neuronal stargazin-like proteins, $\gamma 2, \gamma 3$ and $\gamma 4$; an investigation of their specific localization in human brain and their influence on $\mathrm{Ca}_{\mathrm{V}} 2.1$ voltage-dependent calcium channels expressed in Xenopus oocytes. BMC Neurosci 4:23-41.

Nicoll RA, Tomita S, Bredt DS (2006) Auxiliary subunits assist AMPA-type glutamate receptors. Science 311:1253-1256.

Nishimura W, Yao I, Iida J, Tanaka N, Hata Y (2002) Interaction of synaptic scaffolding molecule and $\beta$-catenin. J Neurosci 22:757-765.

Nishioka H, Mizoguchi A, Nakanishi H, Mandai K, Takahashi K, Kimura K, Satoh-Moriya A, Takai Y (2000) Localization of l-afadin at puncta adhaerentia-like junctions between the mossy fiber terminals and the dendritic trunks of pyramidal cells in the adult mouse hippocampus. J Comp Neurol 424:297-306.

Noebels JL, Qiao X, Bronson RT, Spencer C, Davisson MT (1990) Stargazer: a new neurological mutant on chromosome 15 in the mouse with prolonged cortical seizures. Epilepsy Res 7:129-135.

Ohtsuka T, Hata Y, Ide N, Yasuda T, Inoue E, Inoue T, Mizoguchi A, Takai Y (1999) nRap GEP: a novel neural GDP/GTP exchange protein for rap1 small $G$ protein that interacts with synaptic scaffolding molecule (SSCAM). Biochem Biophys Res Commun 265:38-44.

Pfister S, Przemeck GK, Gerber JK, Beckers J, Adamski J, Hrabe de Angelis M (2003) Interaction of the MAGUK family member Acvrinp1 and the cytoplasmic domain of the Notch ligand Deltal. J Mol Biol 333:229-235.

Price MG, Davis CF, Deng F, Burgess DL (2005) The $\alpha$-amino-3-hydroxyl5-methyl-4-isoxazolepropionate receptor trafficking regulator "stargazin" is related to the claudin family of proteins by its ability to mediate cell-cell adhesion. J Biol Chem 280:19711-19720.

Priel A, Kolleker A, Ayalon G, Gillor M, Osten P, Stern-Bach Y (2005) Stargazin reduces desensitization and slows deactivation of the AMPA-type glutamate receptors. J Neurosci 25:2682-2686.

Qiao X, Chen L, Gao H, Bao S, Hefti F, Thompson RF, Knusel B (1998) Cerebellar brain-derived neurotrophic factor-TrkB defect associated with impairment of eyeblink conditioning in Stargazer mutant mice. J Neurosci 18:6990-6999.

Rouach N, Byrd K, Petralia RS, Elias GM, Adesnik H, Tomita S, Karimzadegan S, Kealey C, Bredt DS, Nicoll RA (2005) TARP $\gamma 8$ controls hippocampal AMPA receptor number, distribution and synaptic plasticity. Nat Neurosci 8:1525-1533.

Rousset M, Cens T, Restituito S, Barrere C, Black JL, McEnery MW, Charnet $\mathrm{P}$ (2001) Functional roles of $\gamma 2, \gamma 3$ and $\gamma 4$, three new $\mathrm{Ca}^{2+}$ channel subunits, in $\mathrm{P} / \mathrm{Q}$-type $\mathrm{Ca}^{2+}$ channel expressed in Xenopus oocytes. J Physiol (Lond) 532:583-593.

Schnell E, Sizemore M, Karimzadegan S, Chen L, Bredt DS, Nicoll RA (2002)
Direct interactions between PSD-95 and stargazin control synaptic AMPA receptor number. Proc Natl Acad Sci USA 99:13902-13907.

Shi SH, Cheng T, Jan LY, Jan YN (2004) The immunoglobulin family member dendrite arborization and synapse maturation 1 (Dasm1) controls excitatory synapse maturation. Proc Natl Acad Sci USA 101:13346-13351.

Shoji H, Tsuchida K, Kishi H, Yamakawa N, Matsuzaki T, Liu Z, Nakamura T, Sugino H (2000) Identification and characterization of a PDZ protein that interacts with activin type II receptors. J Biol Chem 275:5485-5492.

Subauste MC, Nalbant P, Adamson ED, Hahn KM (2005) Vinculin controls PTEN protein level by maintaining the interaction of the adherens junction protein $\beta$-catenin with the scaffolding protein MAGI-2. J Biol Chem 280:5676-5681.

Thompson JD, Higgins DG, Gibson TJ (1994) CLUSTAL W: improving the sensitivity of progressive multiple sequence alignment through sequence weighting, positions-specific gap penalties and weight matrix choice. Nucleic Acids Res 22:4673-4680.

Tomita S, Chen L, Kawasaki Y, Petralia RS, Wenthold RJ, Nicoll RA, Bredt DS (2003) Functional studies and distribution define a family of transmembrane AMPA receptor regulatory proteins. J Cell Biol 161:805-816.

Tomita S, Fukata M, Nicoll RA, Bredt DS (2004) Dynamic interaction of stargazin-like TARPs with cycling AMPA receptors at synapses. Science 303:1508-1511.

Turetsky D, Garringer E, Patneau DK (2005) Stargazin modulates native AMPA receptor functional properties by two distinct mechanisms. J Neurosci 25:7438-7448.

van Ham M, Hendriks W (2003) PDZ domains-glue and guide. Mol Biol Rep 30:69-82.

Vandenberghe W, Nicoll RA, Bredt DS (2005) Stargazin is an AMPA receptor auxiliary subunit. Proc Natl Acad Sci USA 102:485-490.

Wang CY, Chang K, Petralia RS, Wang YX, Seabold GK, Wenthold RJ (2006) A novel family of adhesion-like molecules that interacts with the NMDA receptor. J Neurosci 26:2174-2183.

Wood JD, Yuan J, Margolis RL, Colomer V, Duan K, Kushi J, Kaminsky Z, Kleiderlein JJ, Sharp AH, Ross CA (1998) Atrophin-1, the DRPLA gene product, interacts with two families of WW domain-containing proteins. Mol Cell Neurosci 11:149-160.

Wu X, Hepner K, Castelino-Prabhu S, Do D, Kaye MB, Yuan XJ, Wood J, Ross C, Sawyers CL, Whang YE (2000) Evidence for regulation of the PTEN tumor suppressor by a membrane localized multi-PDZ domain containing scaffold protein MAGI-2. Proc Natl Acad Sci USA 97:4233-4238.

Xu J, Paquet M, Lau AG, Wood JD, Ross CA, Hall RA (2001) $\beta 1$-adrenergic receptor association with the synaptic scaffolding protein membraneassociated guanylate kinase inverted-2 (MAGI-2). Differential regulation of receptor internalization by MAGI-2 and PSD-95. J Biol Chem 76:41310-41317.

Yamada A, Irie K, Deguchi-Tawarada M, Ohtsuka T, Takai Y (2003) Nectindependent localization of synaptic scaffolding molecule (S-SCAM) at the puncta adherentia junctions formed between the mossy fibre terminals and the dendrites of pyramidal cells in the CA3 area of the mouse hippocampus. Genes Cells 8:985-994.

Yamada A, Irie K, Fukuhara A, Ooshio T, Takai Y (2004) Requirement of the actin cytoskeleton for the association of nectins with other cell adhesion molecules at adherens and tight junctions in MDCK cells. Genes Cells 9:843-855.

Yamagata M, Sanes JR, Weiner JA (2003) Synaptic adhesion molecules. Curr Opin Cell Biol 15:621-632.

Yamazaki M, Ohno-Shosaku T, Fukaya M, Kano M, Watanabe M, Sakimura $\mathrm{K}$ (2004) A novel action of stargazin as an enhancer of AMPA receptor activity. Neurosci Res 50:369-374.

Yao I, Hata Y, Ide N, Hirao K, Deguchi M, Nishioka H, Mizoguchi A, Takai Y (1999) MAGUIN, a novel neuronal membrane-associated guanylate kinase-interacting protein. J Biol Chem 274:11889-11896.

Yap CC, Muto Y, Kishida H, Hashikawa T, Yano R (2003) PKC regulates the $\delta 2$ glutamate receptor interaction with S-SCAM/MAGI-2 protein. Biochem Biophys Res Commun 301:1122-1128. 